\title{
OPEN Improving sewage sludge compost process and quality by carbon sources addition
}

\author{
Liqiang Meng ${ }^{1,2}$, Weiguang $\mathrm{Li}^{3,4}$, Shumei Zhang ${ }^{1,2}$, Xiancheng Zhang ${ }^{1}, \mathrm{Yi} \mathrm{Zhao}^{3}$ \& Li Chen ${ }^{3}$
}

In present study, the effects of carbon sources on compost process and quality were evaluated in the lab-scale sewage sludge (SS) composting. The composting experiments were performed for 32 days in $5 \mathrm{~L}$ reactors. The results showed that carbon sources could change the nitrogen conversion and improve the compost quality. Especially, the readily degradable carbon source could promote organic matter degradation, improve nitrogen conversion process and accelerate compost maturation. The addition of glucose and sucrose could increase dissolved organic carbon, $\mathrm{CO}_{2}$ emission, dehydrogenase activity, nitrification and germination index during the SS composting. That's because glucose and sucrose could be quickly used by microbes as energy and carbon source substance to increase activity of microbes and ammonia assimilation. What's more, the $\mathrm{NH}_{3}$ emission was reduced by $26.9 \%$ and $32.1 \%$ in glucose and sucrose treatments, respectively. Therefore, the addition of readily degradable carbon source could reduce $\mathrm{NH}_{3}$ emission and improve compost maturity in the SS composting.

Sewage sludge (SS) is a by-product of wastewater treatment process, which contains a lot of N, P, K and other harmful components, such as heavy metals and pathogenic microorganisms ${ }^{1}$. With the expedited development of urbanization, the sewage treatment capacity is increasing year by year in China, which leads to large amounts of SS cannot be treated effectively in time ${ }^{2,3}$. China's urban SS is growing at a rate of $13 \%$ a year, with annual SS production expected to exceed 60 million tons by 2020, so the efficient and safe disposal of SS has become one of the main problems in China ${ }^{4,5}$. The urgency of SS treatment has been stressed in China's new environmental law and "The Prevention and Control Action Plan of Water Pollution"6.

Aerobic high-temperature composting is one of the effective ways to realize SS reduction, innocuity and reuse, furthermore, its products can be used as organic fertilizer and soil conditioner ${ }^{7,8}$. Admittedly, nitrogen was a key element in compost and could be recycled in agricultural application ${ }^{9}$. However, about $40 \%-80 \%$ nitrogen was lost through $\mathrm{NH}_{3}$ emission in the SS compost process, so much nitrogen loss must reduce compost quality and lead to air pollution ${ }^{10,11}$.

The low carbon-nitrogen ratio of SS is one of main reasons that lead to the severe $\mathrm{NH}_{3}$ emission in the composting process ${ }^{12,13}$. Therefore, in practical application, some substances rich in carbon sources are often added as bulking agent to improve the SS composting ${ }^{14}$. To increase the $\mathrm{C} / \mathrm{N}$ ratio of substrates, lots of carbon-rich amendments, such as biochar, sawdust, spent mushroom substrate and cornstalks were added in composting ${ }^{5,15-17}$. However, the effects of different carbon sources amendment on $\mathrm{NH}_{3}$ emission was significantly different, even some amendment were not satisfying because of poor availability of the materials used ${ }^{18}$. That's could be because the poor availability of amendment cause excessive nitrogen cannot be assimilated by microorganism and promote $\mathrm{NH}_{3}$ emission by microbial reactions ${ }^{19,20}$.

The previous research found that sucrose could improve the ammonia assimilation of microorganism and promote the transform of $\mathrm{NH}_{4}^{+}$into biological nitrogen ${ }^{21,22}$. Few studies of the effects of carbon sources types on $\mathrm{NH}_{3}$ emission in SS composting process have been performed. So, the main objectives of present research were to evaluate the influence of different carbon sources (glucose, sucrose, starch, and cellulose) on physical-chemical properties, organic matter degradation, dehydrogenase activity (DHA), $\mathrm{NH}_{3}$ emission, nitrification index and germination index in SS composting.

\footnotetext{
${ }^{1}$ Institute of Microbiology, Heilongjiang Academy of Sciences, Harbin 150010, China. ${ }^{2}$ Institute of Advanced Technology, Heilongjiang Academy of Sciences, Harbin 150020, China. ${ }^{3}$ School of Environmental Engineering, Harbin Institute of Technology, Box no. 2602, 73 Huanghe Road, Harbin 150090, Heilongjiang, China. ${ }^{4}$ State Key Laboratory of Urban Water Resource and Environment, Harbin Institute of Technology, Harbin 150090, China. ${ }^{\varpi}$ email: hitlwg@126.com
} 


\begin{tabular}{|l|l|l|l|}
\hline & $\mathbf{p H}$ & MC (\%) & OM (\%) \\
\hline SS & $7.34 \pm 0.21$ & $81.45 \pm 1.12$ & $56.23 \pm 0.14$ \\
\hline Pumice & $6.83 \pm 0.15$ & $0.37 \pm 0.21$ & $0.56 \pm 0.02$ \\
\hline Glucose & $7.04 \pm 0.14$ & $1.19 \pm 0.10$ & $99.34 \pm 0.43$ \\
\hline Sucrose & $6.96 \pm 0.54$ & $0.34 \pm 0.65$ & $99.52 \pm 0.09$ \\
\hline Starch & $6.83 \pm 0.35$ & $1.42 \pm 0.15$ & $98.87 \pm 0.54$ \\
\hline Cellulose & $6.94 \pm 0.28$ & $0.54 \pm 0.53$ & $98.13 \pm 0.45$ \\
\hline
\end{tabular}

Table 1. The characteristics of the raw materials. The results are the mean \pm standard deviation $(\mathrm{n}=3) . M C$ moisture content, $O M$ organic matter.

\section{Materials and methods}

Composting system. The dewatered SS were collected from a local sewage disposal plant in Harbin, China. Pumice was used as bulking agent, which was a light volcanic rock with no organic matter (OM). First $10 \mathrm{~kg}$ dewatered SS were mixed with $5 \mathrm{~kg}$ pumice, and then the mixture was divided into five parts. One of them was set as the control treatment without extra carbon source, and other four treatments were added $4 \%$ (carbon source/SS) sucrose, glucose, cellulose and starch. The composting material of each treatment was mixed evenly before the composting begins and put into respective reactors. The characteristics of raw materials were shown in Table 1. The reactors consisted of plastic cylinders with inner diameter $300 \mathrm{~mm}$ and height $600 \mathrm{~mm}$ respectively, and the other description were reported in previous literature ${ }^{5}$. In order to reduce the heat loss during composting, the reactors were put into a water tank whose temperature was set below $1 \sim 3{ }^{\circ} \mathrm{C}$ of contol treatment ${ }^{20}$. The air was ventilated from the bottom of reactors by a air pump with $0.4 \mathrm{~L} / \mathrm{min}$ aeration rate.

Sampling protocol. The compost experiment was conducted for 32 days, and the samples were collected on Day $1,3,5,7,9,13,18,23$ and 32, respectively. The composting samples were collected from upper, middle and lower part of every reactor using the methods of quatering. The three $10 \mathrm{~g}$ samples were combined into one composite sample, after mixed thoroughly, the composite sample was divided into two parts on average. The first part was used to determine the moisture content through drying by an oven, and then the dried samples were used to determine organic matter $(\mathrm{OM})$ content. The second part was stored at $4{ }^{\circ} \mathrm{C}$ for the measurement of dissolved organic carbon (DOC), DHA, $\mathrm{NH}_{4}{ }^{+}, \mathrm{NO}_{3}{ }^{-}$and germination index, and all the samples were carried out in triplicate for variance analysis.

Analysis methods. The OM contents were determined by measuring the loss of dry-solid mass after igniting at $550{ }^{\circ} \mathrm{C}$ for $5 \mathrm{~h}$ in a muffle furnace. The exhausted gas was obtain through a aluminium sampling bag everyday used the method of Maulini et al. ${ }^{23}$. The $\mathrm{NH}_{3}$ and $\mathrm{CO}_{2}$ were trapped by boric acid and natrium hydroxydatum solutions, respectively, then determined by titration ${ }^{24}$. The fresh sample was mixed with distilled water at 1:10 mass ratio (samples:distilled water) and oscillated in a shaker for $1 \mathrm{~h}$. Then the mixture was centrifuged at $12,000 \mathrm{rpm}$ for $5 \mathrm{~min}$ and the supernatant was filtered by $0.45 \mu \mathrm{m}$ filter membrane to obtain the water extracts of sample ${ }^{25}$. The DOC content in the water extracts was measured by a Biotector TOC-B7000 TOC analyser (Hach, America). The DHA of sample was determined by the methods of Tiquia ${ }^{26}$. $\mathrm{NH}_{4}{ }^{+}$and $\mathrm{NO}_{3}{ }^{-}$were extracted in a $2 \mathrm{M} \mathrm{KCl}$ (sample at $1 \%$ mass ratio) and determined by colorimetry methods refer to the reports of Belyaeva and Haynes ${ }^{27}$. The germination indexs (GI) were measured by pakchoi seeds and water extracts, twenty pakchoi seeds were distributed on the filter paper in a sterile dish $(9 \mathrm{~cm}$ diameter), then $5 \mathrm{~mL}$ of the compost water extract was added to the filter paper and incubated at $20^{\circ} \mathrm{C}$ for 3 days in dark. The computational method according to the author's previous method ${ }^{5}$. The data revealed in present paper were obtained from the average of three parallel samples and then were calculated by Microsoft Excel 2017 and the analyses of statistical were completed by SPSS 16.0 .

\section{Results and discussion}

Organic matter and dehydrogenase activity. The degradation rate of OM directly reflects the metabolism velocity of the microorganisms during the composting process ${ }^{28}$. The initial OM contents in carbon source treatment were higher than that in control treatment which was $61.3 \%$ (Fig. 1a). The OM contents in carbon source treatments were in the range of $65.3-67.3 \%$, which showed the difference among them was not significant. The OM degraded rapidly of all treatments during the thermophilic phase of composting, and the OM contents dropped to $45.8 \%$ (control), $44.8 \%$ (glucose), $47.1 \%$ (sucrose), 49.2\% (starch) and 51.3\% (cellulose) respectively at the end of the thermophilic phase (Day 13). During mesophilic phase and thermophilic phase, the loss of OM contents in the control treatment and the cellulose treatment were $15.5 \%$ and $15.4 \%$, respectively. However, the losses in glucose and the sucrose treatment were higher than the other treatments, were $21.9 \%$ and $20.2 \%$, respectively. Moreover, the loss of starch treatment was slightly higher than that in control treatment was $16.1 \%$. That's because the glucose and sucrose belong to easily degradable carbon sources which were easy to be used by microorganisms, could increase the activity of composting microorganisms and promote the degradation of OM. Contrarily, owing to the complex macromolecular structure of cellulose that was not easy to be used by microorganisms, the addition of cellulose has the least impact on the degradation rate of $\mathrm{OM}^{11}$. At the end of composting, the lowest OM degradation rates also appeared in the glucose and the sucrose treatment, which 

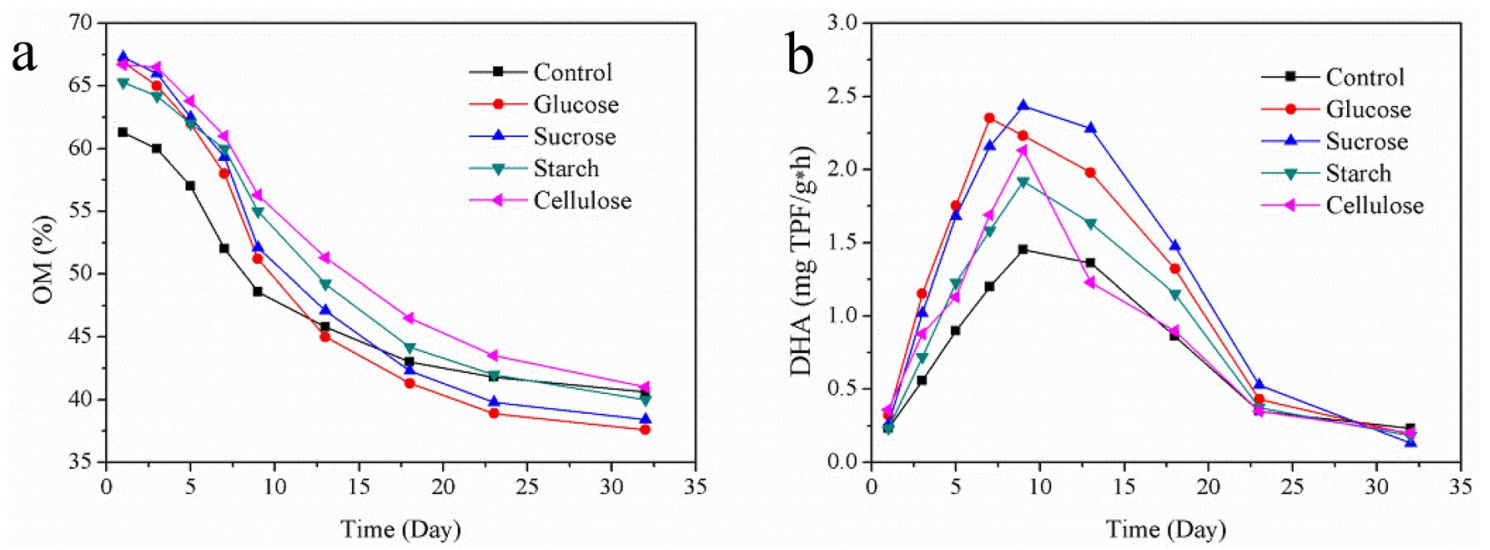

Figure 1. Evolutions of OM (a) and DHA (b) in five treatments.
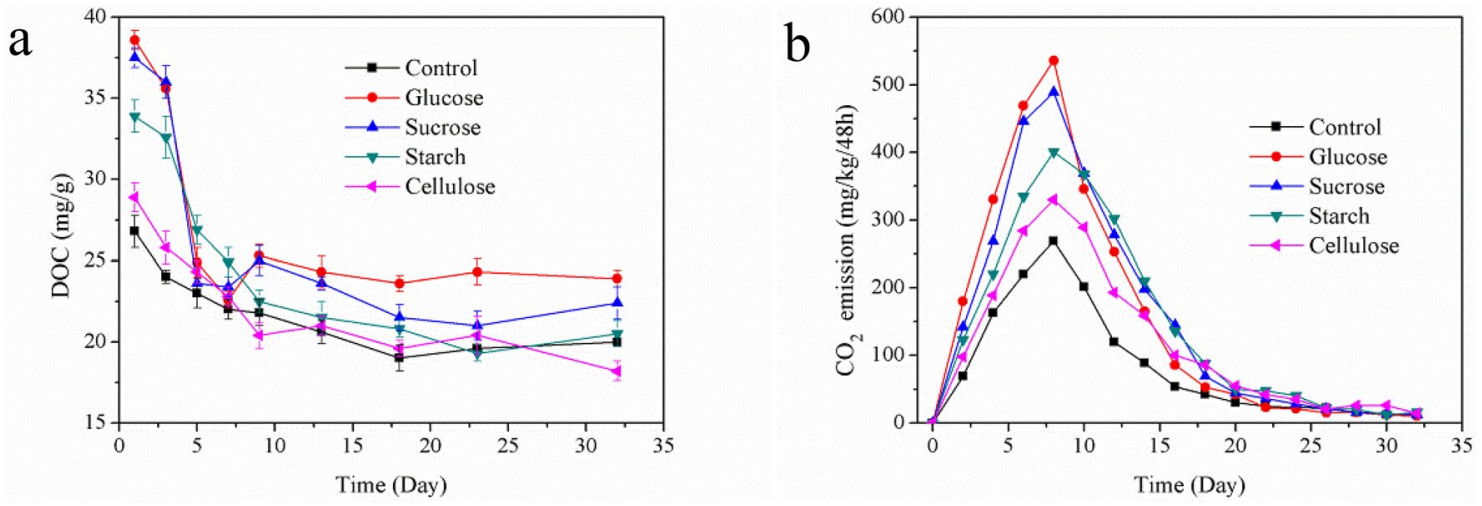

Figure 2. Evolutions of DOC (a) and $\mathrm{CO}_{2}$ emission (b) in five treatments.

were $37.6 \%$ and $38.4 \%$, respectively. However, the differences between the other three treatments were not significant in the range of 40.1-41.2\%. Obviously, the addition of glucose and sucrose would promote the metabolic activities of microorganisms and accelerate the degradation of $\mathrm{OM}$ in composting.

Dehydrogenase is a collective name for a series of metabolic reaction enzymes that catalyze the degradation of OM to produce ATP inside the microbial cells ${ }^{29}$. Therefore, DHA has been recognized as an important parameter that can react to the speed of biochemical reactions during composting ${ }^{30}$. The evolution of DHA is shown in Fig. 1b, the DHA of each treatment was extremely sensitive to temperature, what's more, they showed a positive correlation ${ }^{31}$. The DHA increased in the mesophilic phase and thermophilic phase in all treatments, and reached their peak values in the thermophilic phase, then the DHA gradually decreased in the cooling phase until the end of composting. The results showed that the addition of carbon source significantly increased the DHA, and the different raise between types of carbon sources were significant. The DHA of glucose treatment reached peak on Day 7 and the peak value of $2.35 \mathrm{mg} \mathrm{TPF} / \mathrm{g} \mathrm{h}$, while the other four treatments reached the peak on Day 9. The peak value of sucrose treatment was $2.44 \mathrm{mg} \mathrm{TPF} / \mathrm{g}$ h that was the highest, followed by the starch, cellulose and control treatment which were $1.92 \mathrm{mg} \mathrm{TPF} / \mathrm{g} \mathrm{h}, 2.13 \mathrm{mg}$ TPF/g h, and $1.45 \mathrm{mg} \mathrm{TPF} / \mathrm{g} \mathrm{h}$, respectively. Nikaeen et al..$^{30}$ also reported that DHA had been increasing during the initial phase of composting, and then gradually decreased with decreasing temperature in the cooling phase. Previous reports had confirmed that DHA showed positive correlation with the culturable microorganisms in composting ${ }^{5}$, therefore, the addition of carbon sources could provide energy materials for the compost microorganisms, promote the microorganisms growth and improve DHA in compost. Similar phenomenon had been found by Zhang et al. ${ }^{32}$, who reported that the nutrients in the bulking agent could promote the metabolism of compost microorganisms and increase their biological activity and biomass. In present study, as readily degradable carbon source glucose and sucrose could be quickly used by microorganisms, so the DHA were stronger than those in other treatments, this results was consistent with previous reports ${ }^{33,34}$.

Dissolved organic carbon and $\mathrm{CO}_{2}$ emission. DOC mainly includes small molecule, simple structure and water soluble carbon source materials, so it is easily used by microorganisms to participate in the biochemical reaction of composting ${ }^{35}$. The change of DOC in the composting could indirectly reflect the metabolism of compost microorganisms, and DOC had a certain relationship with the degradation of OM and the maturity of the compost product, so DOC could also be used to evaluate the stability of composting product ${ }^{36}$. The evolutions of DOC in five treatments are showed in Fig. 2a, the differences of initial DOC concentrations between five 
treatments were significant, which was closely related to the type of extra carbon source. The concentrations of DOC of the glucose and sucrose treatments were significantly higher than those of other treatments, because the glucose and sucrose were easily degradable carbon source, and their water solubility directly led to the increase in DOC concentration. However, the initial DOC concentration of starch treatment was lower than that of the glucose and sucrose treatments, and cellulose and control treatments had the lowest initial DOC concentrations, because the larger molecular structures in starch and cellulose could not be easily soluble in composting ${ }^{20}$. In the early stages (Day 1-7) of composting, the DOC concentration of all treatments decreased rapidly, especially in the glucose and sucrose treatments, which decreased from $38.6 \mathrm{mg} / \mathrm{g}$ and $37.5 \mathrm{mg} / \mathrm{g}$ to $22.6 \mathrm{mg} / \mathrm{g}$ and $23.4 \mathrm{mg} / \mathrm{g}$, respectively. And the decreases were $16.0 \mathrm{mg} / \mathrm{g}$ and $14.1 \mathrm{mg} / \mathrm{g}$, which were much higher than those of other treatments. In addition, the DOC concentrations of glucose and sucrose treatments experienced a slight increase on the Day 7-9 in thermophilic phase, this might be because the readily degradable carbon source promoted the degradation of the original OM of the SS composting and the release rate of DOC from OM degradation was higher than the degradation rate of it. The degradation of DOC in the cellulose treatment was similar to that of the control treatment, which was fast in the mesophilic phase and thermophilic phase of the compost. The DOC concentrations of all treatments remained stable during the cooling phase, and the final DOC concentration was in the range of $18.2-23.9 \mathrm{mg} / \mathrm{g}$.

$\mathrm{CO}_{2}$ was generated during the degradation of $\mathrm{OM}$ by microorganisms in the composting, so the release rate of $\mathrm{CO}_{2}$ could reflect the activity of microorganisms and the degradation rate of $\mathrm{OM}^{37}$. The evolutions of the $\mathrm{CO}_{2}$ emission in the five treatments are shown in Fig. 2b. The change trends of $\mathrm{CO}_{2}$ emission in all treatments were similar, but the amounts of $\mathrm{CO}_{2}$ emission were significantly different. All the amounts of $\mathrm{CO}_{2}$ emission increased rapidly in mesophilic and thermophilic phase, and reached their respective peaks on the Day 8 of composting. Thereinto, the biggest $\mathrm{CO}_{2}$ emission amount was $536.3 \mathrm{mg} / \mathrm{kg} / 48 \mathrm{~h}$ in glucose treatment, followed by $489.6 \mathrm{mg} /$ $\mathrm{kg} / 48 \mathrm{~h}$ in sucrose treatment, $401.2 \mathrm{mg} / \mathrm{kg} / 48 \mathrm{~h}$ in starch treatment, $330.6 \mathrm{mg} / \mathrm{kg} / 48 \mathrm{~h}$ in cellulose treatment and $269.5 \mathrm{mg} / \mathrm{kg} / 48 \mathrm{~h}$ in control treatment. After the peaks, the amount of $\mathrm{CO}_{2}$ emission in each treatment gradually decreased until the end of composting, and only a small amount of $\mathrm{CO}_{2}$ was volatilized during Day 20-32 of composting. Obviously, the addition of extra carbon source promotes the $\mathrm{CO}_{2}$ emission during the composting process. What's more, as easily degradable carbon source, glucose and sucrose were easier to be used by microorganisms, whose promotions for $\mathrm{CO}_{2}$ emission were stronger than those in other treatments. The accumulative amounts of $\mathrm{CO}_{2}$ emission were $2557.2 \mathrm{mg} / \mathrm{kg}$ and $2576.6 \mathrm{mg} / \mathrm{kg}$ in glucose and sucrose treatments, which were $86.9 \%$ and $88.3 \%$ higher than that in the control treatment at $1368.2 \mathrm{mg} / \mathrm{kg}$, respectively. The accumulative amounts of $\mathrm{CO}_{2}$ emission in starch and cellulose treatments were $2391.6 \mathrm{mg} / \mathrm{kg}$ and $1947.2 \mathrm{mg} / \mathrm{kg}$, respectively, which were lower than those in the glucose and sucrose treatments and higher $74.8 \%$ and $42.3 \%$ than the control treatment. Because the complex macromolecular structure of cellulose was not easily used by microorganisms, the promotion of $\mathrm{CO}_{2}$ emission was negligible. Moreover, starch was easier to be used by microorganisms than cellulose, so the $\mathrm{CO}_{2}$ emission in starch treatment was higher than that in cellulose treatment.

$\mathrm{NH}_{4}{ }^{+}, \mathrm{NH}_{3}$ emission, $\mathrm{NO}_{3}{ }^{-}$, Nitrification index. $\mathrm{NH}_{4}{ }^{+}$would be produced through the ammonification of microorganisms with OM degradation in the SS composting process ${ }^{27}$. The evolutions of $\mathrm{NH}_{4}{ }^{+}$are shown in Fig. 3a, the $\mathrm{NH}_{4}{ }^{+}$concentrations of all treatments increased rapidly during the mesophilic phase and reached their respective peaks on the Day 9 of thermophilic phase. In besides, the change trend of each treatment was similar, because the increase in $\mathrm{NH}_{4}{ }^{+}$concentration was mainly caused by the rapid degradation of nitrogencontaining organic compounds ${ }^{38}$. The $\mathrm{NH}_{4}{ }^{+}$concentrations of control treatment were significantly higher than those of the carbon source treatments, and it's peak value was $4.21 \mathrm{~g} / \mathrm{kg}$, which were $1.22,1.28,1.08$ and 1.04 times of that in glucose, sucrose, starch, and cellulose treatments, respectively. In the mesophilic phase, with the temperature increased the microorganisms multiplied rapidly, the DHA also increased rapidly (introduced in "Organic matter and dehydrogenase activity") and the ammonification of microorganisms played a major role in nitrogen conversion process. The peak concentrations of $\mathrm{NH}_{4}{ }^{+}$of the glucose and sucrose treatments were much lower than that of the control treatment, because the microorganisms could more easily use the degradable carbon sources and promote the ammonia assimilation, that transformed the $\mathrm{NH}_{4}{ }^{+}-\mathrm{N}$ into biological nitrogen. On the contrary, the contents of DOC in the cellulose and control treatments were lower than the other treatments (introduced in "Dissolved organic carbon and $\mathrm{CO}_{2}$ emission"), so a large amount of nitrogen were converted into $\mathrm{NH}_{4}^{+}$by ammonification.

After the peak values, the $\mathrm{NH}_{4}{ }^{+}$concentrations in all treatments decreased rapidly, because high temperature and the gradually rising $\mathrm{pH}$ value promoted the conversion of $\mathrm{NH}_{4}{ }^{+}$to $\mathrm{NH}_{3}$ and released into the atmosphere eventually ${ }^{24}$. Only a small $\mathrm{NH}_{4}{ }^{+}$could be detected at the end of composting, and the $\mathrm{NH}_{4}{ }^{+}$concentration in control and the cellulose treatments were slightly higher than those in other treatments, which were $0.65 \mathrm{~g} / \mathrm{kg}$ and $0.69 \mathrm{~g} / \mathrm{kg}$, respectively. Ros et al. ${ }^{39}$ also reported that the $\mathrm{NH}_{4}{ }^{+}$concentration gradually increased during the first 3-6 weeks of composting, and then gradually decreased due to $\mathrm{NH}_{3}$ emission until the end of composting.

$\mathrm{NH}_{3}$ emission is one of the main reasons for the nitrogen loss, and the too low carbon-nitrogen ratio of the sewage sludge is an important factor that causes a large amount of $\mathrm{NH}_{3}$ emission during SS composting process ${ }^{40}$. Adding extra carbon source could effectively control nitrogen loss in SS composting ${ }^{22}$, however, the effects of different carbon sources on $\mathrm{NH}_{3}$ emission were different.

The $\mathrm{NH}_{3}$ emission rate increased rapidly with the temperature rising in the early stage, then reached their respective peaks in thermophilic phase. The peak value of $\mathrm{NH}_{3}$ emission of control treatment was $320.7 \mathrm{mg} /$ $\mathrm{kg} / 48 \mathrm{~h}$, followed by $290.6 \mathrm{mg} / \mathrm{kg} / 48 \mathrm{~h}$ in cellulose treatment, $239.5 \mathrm{mg} / \mathrm{kg} / 48 \mathrm{~h}$ in starch treatment, $197.5 \mathrm{mg} /$ $\mathrm{kg} / 48 \mathrm{~h}$ in glucose treatment and $185.8 \mathrm{mg} / \mathrm{kg} / 48 \mathrm{~h}$ in sucrose treatment (Fig. 3b). The emission rate of $\mathrm{NH}_{3}$ had a positive correlation with the concentration of $\mathrm{NH}_{4}{ }^{+}$in the composting. Therefore, the $\mathrm{NH}_{3}$ emission amount of each treatment increased sharply when the concentrations of $\mathrm{NH}_{4}{ }^{+}-\mathrm{N}$ were high in the thermophilic phase, 
a
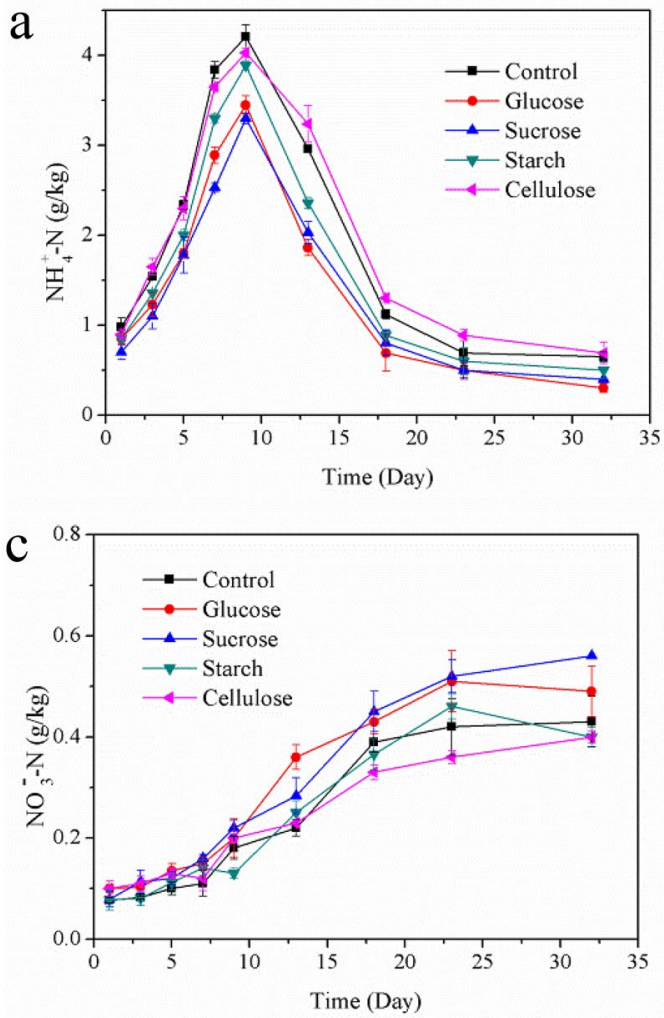
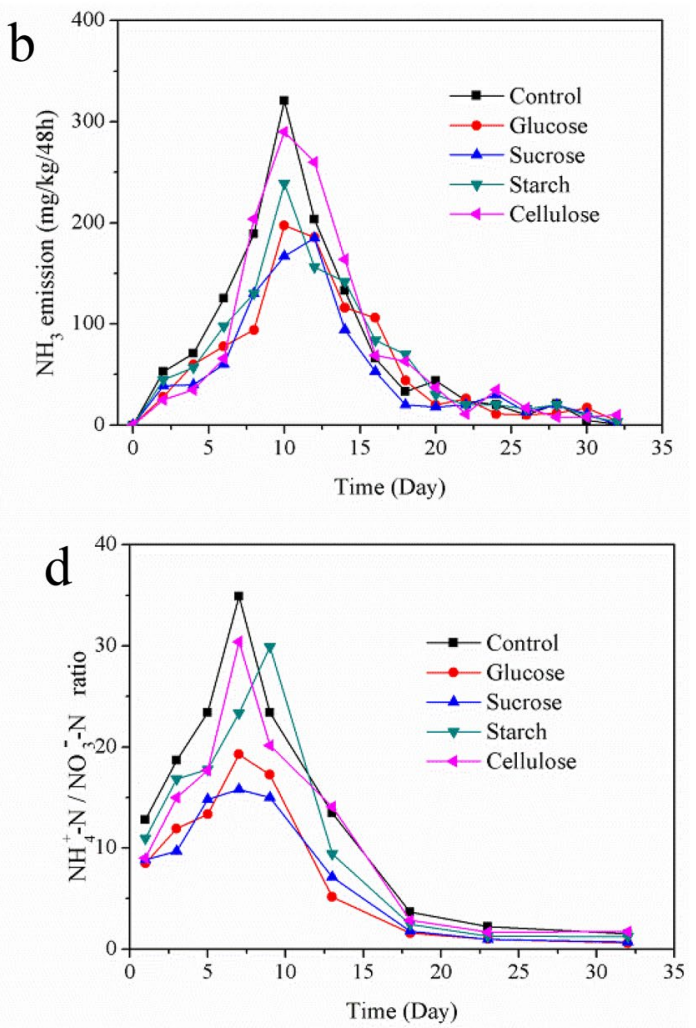

Figure 3. Evolution of $\mathrm{NH}_{4}{ }^{+}-\mathrm{N}(\mathbf{a}), \mathrm{NH}_{3}$ emission (b), $\mathrm{NO}_{3}{ }^{-} \mathrm{N}(\mathbf{c})$ and $\mathrm{NH}_{4}{ }^{+}-\mathrm{N}^{-} \mathrm{NO}_{3}{ }^{-} \mathrm{N}(\mathbf{d})$ in five treatments.

and the $\mathrm{NH}_{3}$ emission was also gradually flattening when the concentration of $\mathrm{NH}_{4}{ }^{+}$decreased in the cooling phase. The addition of carbon source changed the metabolic pathway of nitrogen, concretely, it could affect the microbial ammonification which led directly to $\mathrm{NH}_{3}$ emission during the composting process. For example, the peak of the sucrose treatment appeared on Day 12, and the peaks of the other 4 treatments appeared on Day 10. Moreover, the addition of extra carbon source significantly inhibited the $\mathrm{NH}_{3}$ emission, especially in the readily degradable carbon source treatments, the $\mathrm{NH}_{3}$ emission peaks were reduced by $38.4 \%$ and $42.3 \%$ in glucose and sucrose treatments compared with the control treatment, respectively.

In the whole composting process, the cumulative $\mathrm{NH}_{3}$ emission of sucrose treatment was $900.3 \mathrm{mg} / \mathrm{kg}$, which was the least of five treatments, followed by $968.8 \mathrm{mg} / \mathrm{kg}$ in glucose treatment, $1168.5 \mathrm{mg} / \mathrm{kg}$ in starch treatment, $1278.3 \mathrm{mg} / \mathrm{kg}$ in cellulose treatment and $1325.9 \mathrm{mg} / \mathrm{kg}$ in control treatment. In addition, the cumulative $\mathrm{NH}_{3}$ emission was decreased by $32.1 \%, 26.9 \%, 11.8 \%$ and $3.6 \%$ compared with the control treatment in sucrose, glucose, starch and cellulose treatments, respectively. That's because glucose and sucrose were easily used by microorganisms, and could participate in the biochemical reaction of composting faster. Moreover, the readily degradable carbon source could increase the DOC concentration (introduced in "Dissolved organic carbon and $\mathrm{CO}_{2}$ emission") and improve the biodegradability of the carbon source, so more $\mathrm{NH}_{4}{ }^{+}$was converted to bio-nitrogen fixed in the compost.

The nitrification in the composting process could be evaluated by detecting the $\mathrm{NO}_{3}{ }^{-}$concentration. As shown in Fig. $3 \mathrm{c}$, the $\mathrm{NO}_{3}{ }^{-}$concentrations of all the treatments were lower than the $\mathrm{NH}_{4}{ }^{+}$concentrations throughout the composting process, especially during mesophilic phase and thermophilic phase. The $\mathrm{NO}_{3}{ }^{-}$concentration was closely related to the activity of nitrifying microorganisms, but the activity of nitrifying microorganisms was inhibited by high temperature and high $\mathrm{NH}_{4}{ }^{+}$concentration, that's why the $\mathrm{NO}_{3}{ }^{-}$concentration were so low during the thermophilic phase. During the first 7 days of composting, the $\mathrm{NO}_{3}{ }^{-}$concentration of each treatment was at a low level $(0.07-0.16 \mathrm{~g} / \mathrm{kg})$. The $\mathrm{NO}_{3}{ }^{-}$concentrations in carbon source treatment was slightly higher than that in control treatment, then difference among the carbon source treatments was not significant. During the cooling phase, the $\mathrm{NO}_{3}{ }^{-}$concentrations of all treatments began to increase as the temperature decreased. The $\mathrm{NO}_{3}^{-}$concentrations of glucose and sucrose treatment was significantly higher than that of control, while the differences among starch, cellulose and control treatment were not significant. The $\mathrm{NO}_{3}{ }^{-}$concentrations of all treatments reached a stable state at end of composting, and the highest $\mathrm{NO}_{3}{ }^{-}$concentration was $0.56 \mathrm{~g} / \mathrm{kg}$ in sucrose treatment, followed by $0.43 \mathrm{~g} / \mathrm{kg}$ in glucose treatment, $0.31 \mathrm{~g} / \mathrm{kg}$ in starch treatment, $0.24 \mathrm{~g} / \mathrm{kg}$ in cellulose treatment and $0.25 \mathrm{~g} / \mathrm{kg}$ in control treatment. With the decrease of temperature and the $\mathrm{NH}_{3}$ emission in the cooling phase, the increase of nitrification in all the treatments caused $\mathrm{NO}_{3}{ }^{-}$concentration raised, and the difference between glucose and sucrose treatments was not significant. Their change trends were similar, could be because the glucose and sucrose as easily degradable carbon sources were exhausted during mesophilic phase and thermophilic phase. 


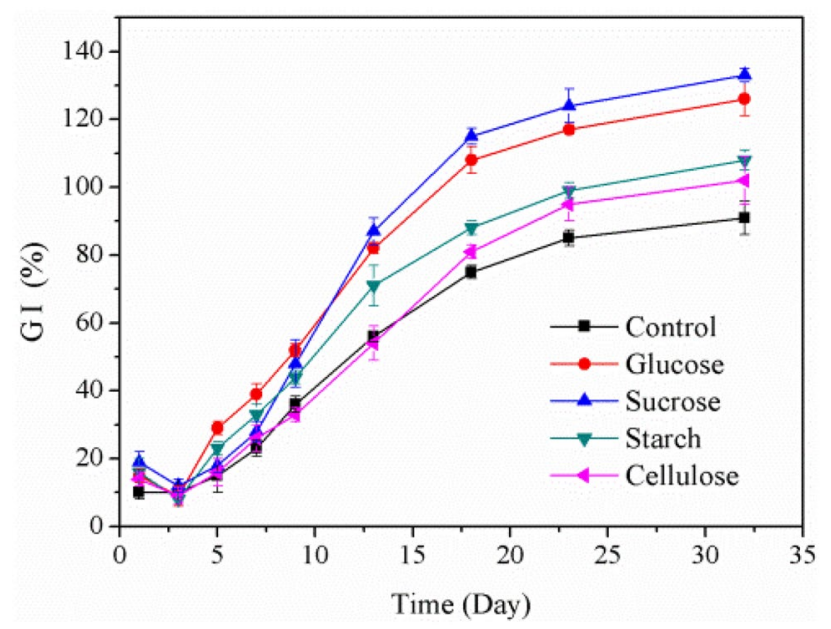

Figure 4. Evolution of GI in five treatments.

The nitrification index was defined as the ratio of $\mathrm{NH}_{4}{ }^{+}$to $\mathrm{NO}_{3}^{-}$, which had been widely used in the evaluation of compost maturity ${ }^{41}$. As shown in Fig. $3 \mathrm{~d}$, the nitrification index of each treatment reached its peak in thermophilic phase, that's because the OM rapidly degraded during this period and the $\mathrm{NH}_{4}{ }^{+}$concentration remained at a high level. After the thermophilic phase, the nitrification index decreased rapidly as the temperature decreased, because the degradation rate of OM became slower, and the compost gradually completed maturation. Moreover, all the treatments reached maturity on Day 23 of the composting. According to Das et al's reports, the nitrification index of less than 0.5 indicated that the compost had reached "completely mature" state at the end of composting, the nitration index between 0.5 and 3.0 indicated that the compost had reached a "mature" state, and the nitrification index greater than 3.0 indicated that the compost had not reached a mature. In present study, all carbon source treatments reached maturity on Day 18 of composting. And the minimum nitrification index was 1.60 in glucose treatment, followed by 1.78 in sucrose treatment, 2.43 in starch treatment and 2.85 in cellulose treatment, while the control treatment was still in immature state with a nitration index of 3.69.

Germination index. Germination index (GI) is a biological activity index commonly used to evaluate compost maturity, and it can intuitively reflect the phytotoxicity change of compost. As shown in Fig. 4, all the GI decreased during first two days of composting, which was due to the production of some $\mathrm{NH}_{4}^{+}$and lowmolecular-weight short-chain volatile fatty acids in the early stage of composting. Similar phenomenon had been found by Guo et al. ${ }^{42}$, who reported that the seed GI was at a low level in early stage when they studied the co-composting of corn straw and pig manure. It's reported that when the GI of the compost material exceeded $80 \%$, it indicated that the compost product had no phytotoxicity and reached the maturity state ${ }^{43}$. The GI of all treatments increased rapidly after Day 3 of composting, which might be due to toxic substances degradation and $\mathrm{NH}_{3}$ emission. Importantly, the GI of the carbon source treatment was higher than that of control, then GI of the carbon source treatments reached over $80 \%$ on Day 18 of composting, concretely, the highest GI was $115.2 \%$ in sucrose treatment, followed by $108.9 \%$ in glucose treatment, $88.3 \%$ in starch treatment, $81.6 \%$ in cellulose treatment, and only $74.7 \%$ in control treatment. The GI of all treatments exceeded $80 \%$ on Day 23 of composting, indicating all the treatments reached no phytotoxicity and mature state. Obviously, the addition of extra carbon sources, especially easily degradable carbon sources, could promote the compost maturation, and the compost could dephytotoxicize earlier.

\section{Conclusions}

The addition of extra carbon sources could improve the nitrogen conversion and compost quality. Especially, glucose and sucrose, as readily degradable carbon source promoted OM degradation and the maturation of composting, increased DOC contents, $\mathrm{CO}_{2}$ emission, DHA, nitrification index and GI in the SS compost. Above all, the addition of sucrose and glucose reduced the $\mathrm{NH}_{3}$ emission by $32.1 \%$ and $26.9 \%$, respectively. Nevertheless, it's recommended that suitable alternatives for glucose and sucrose, such as beet pulp and molasses wastes containing readily degradable carbon sources should be researched to decrease production costs in future research.

Received: 29 October 2020; Accepted: 25 November 2020

Published online: 14 January 2021

\section{References}

1. Głąb, T. et al. Fertilization effects of compost produced from maize, sewage sludge and biochar on soil water retention and chemical properties. Soil Tillage Res. 197, 104493 (2020).

2. Ma, C. et al. Influence of matured compost inoculation on sewage sludge composting: Enzyme activity, bacterial and fungal community succession. Bioresour. Technol. 294, 122165 (2019). 
3. Robledo, M. et al. Assessment of bacterial and fungal communities in a full-scale thermophilic sewage sludge composting pile under a semipermeable cover. Bioresour. Technol. 298, 122550 (2020).

4. Li, H. et al. The fate of antibiotic resistance genes during co-composting of swine manure with cauliflower and corn straw. Bioresour. Technol. 300, 122669 (2020).

5. Meng, L. et al. Feasibility of co-composting of sewage sludge, spent mushroom substrate and wheat straw. Bioresour. Technol. 226, 39-45 (2017).

6. Du, J. et al. Insight into the potentiality of big biochar particle as an amendment in aerobic composting of sewage sludge. Bioresour. Technol. 288, 121469 (2019).

7. Bialobrzewski, I. et al. Model of the sewage sludge-straw composting process integrating different heat generation capacities of mesophilic and thermophilic microorganisms. Waste Manag. 43, 72-83 (2015).

8. Bian, R. et al. Co-composting of municipal solid waste mixed with matured sewage sludge: The relationship between $\mathrm{N} 2 \mathrm{O}$ emissions and denitrifying gene abundance. Chemosphere 189, 581-589 (2017).

9. Ezzariai, A. et al. Evaluation of the antibiotics effects on the physical and chemical parameters during the co-composting of sewage sludge with palm wastes in a bioreactor. Waste Manag. 68, 388-397 (2017).

10. Tang, J. et al. Nitrification plays a key role in $\mathrm{N} 2 \mathrm{O}$ emission in electric-field assisted aerobic composting. Bioresour. Technol. 297, $122470(2020)$

11. Toledo, M. et al. Co-composting of sewage sludge and eggplant waste at full scale: Feasibility study to valorize eggplant waste and minimize the odoriferous impact of sewage sludge. J. Environ. Manage 247, 205-213 (2019).

12. Chen, Y. et al. Utilization of solar energy in sewage sludge composting: fertilizer effect and application. Waste Manag. 34(11), 2014-2021 (2014).

13. Malińska, K., Zabochnicka-Świątek, M. \& Dach, J. Effects of biochar amendment on ammonia emission during composting of sewage sludge. Ecol. Eng. 71, 474-478 (2014).

14. Li, W. et al. Nitrogen loss reduction by adding sucrose and beet pulp in sewage sludge composting. Int. Biodeterior. Biodegr. 124, 297-303 (2017).

15. Awasthi, M. K. et al. New insight with the effects of biochar amendment on bacterial diversity as indicators of biomarkers support the thermophilic phase during sewage sludge composting. Bioresour. Technol. 238, 589-601 (2017).

16. Li, Y. \& Li, W. Nitrogen transformations and losses during composting of sewage sludge with acidified sawdust in a laboratory reactor. Waste Manag. Res. 33(2), 139-145 (2015).

17. Yang, F., Li, G. X., Yang, Q. Y. \& Luo, W. H. Effect of bulking agents on maturity and gaseous emissions during kitchen waste composting. Chemosphere 93(7), 1393-1399 (2013).

18. Li, Y. et al. New insights into the interactions between carbon dioxide and ammonia emissions during sewage sludge composting. Bioresour. Technol. 136, 385-393 (2013).

19. Mao, H. et al. Effects of four additives in pig manure composting on greenhouse gas emission reduction and bacterial community change. Bioresour. Technol. 292, 121896 (2019).

20. Meng, L. et al. Effect of different extra carbon sources on nitrogen loss control and the change of bacterial populations in sewage sludge composting. Ecol. Eng. 94, 238-243 (2016).

21. Meng, L. et al. Effects of sucrose amendment on ammonia assimilation during sewage sludge composting. Bioresour. Technol. 210, 160-166 (2016).

22. Meng, L. et al. Improving sewage sludge composting by addition of spent mushroom substrate and sucrose. Bioresour. Technol. 253, 197-203 (2018).

23. Maulini-Duran, C., Artola, A., Font, X. \& Sánchez, A. Gaseous emissions in municipal wastes composting: Effect of the bulking agent. Bioresour. Technol. 172, 260 (2014).

24. Li, Y. et al. Ammonia emissions and biodegradation of organic carbon during sewage sludge composting with different extra carbon sources. Int. Biodeterior. Biodegr. 85, 624-630 (2013).

25. Hachicha, R. et al. Co-composting of spent coffee ground with olive mill wastewater sludge and poultry manure and effect of Trametes versicolor inoculation on the compost maturity. Chemosphere 88(6), 677-682 (2012).

26. Tiquia, S. M. Microbiological parameters as indicators of compost maturity. J. Appl. Microbiol. 99(4), 816-828 (2005).

27. Belyaeva, O. N. \& Haynes, R. J. Chemical, microbial and physical properties of manufactured soils produced by co-composting municipal green waste with coal fly ash. Bioresour. Technol. 100(21), 5203-5209 (2009).

28. Cai, L., Chen, T. B., Gao, D. \& Yu, J. Bacterial communities and their association with the bio-drying of sewage sludge. Water Res. 90, 44-51 (2016).

29. Zhang, L. \& Sun, X. Changes in physical, chemical, and microbiological properties during the two-stage co-composting of green waste with spent mushroom compost and biochar. Bioresour. Technol. 171, 274-284 (2014).

30. Nikaeen, M. et al. Respiration and enzymatic activities as indicators of stabilization of sewage sludge composting. Waste Manag. 39, 104-110 (2015).

31. Wang, K. et al. Spatial distribution of dynamics characteristic in the intermittent aeration static composting of sewage sludge. Bioresour. Technol. 102(9), 5528-5532 (2011).

32. Zhang, L., Sun, X., Tian, Y. \& Gong, X. Effects of brown sugar and calcium superphosphate on the secondary fermentation of green waste. Bioresour. Technol. 131, 68-75 (2013).

33. Zhang, L. \& Sun, X. Addition of seaweed and bentonite accelerates the two-stage composting of green waste. Bioresour. Technol. 243, 154-162 (2017).

34. Zhang, L. \& Sun, X. Improving green waste composting by addition of sugarcane bagasse and exhausted grape marc. Bioresour. Technol. 218, 335-343 (2016).

35. Awasthi, M. K. et al. Role of Ca-bentonite to improve the humification, enzymatic activities, nutrient transformation and end product quality during sewage sludge composting. Bioresour. Technol. 262, 80-89 (2018).

36. Jiang, J. et al. Evaluation of total greenhouse gas emissions during sewage sludge composting by the different dicyandiamide added forms: Mixing, surface broadcasting, and their combination. Waste Manag. 81, 94-103 (2018).

37. Scoton, E. J., Battistelle, R. A. G., Bezerra, B. S. \& Akutsu, J. A sewage sludge co-composting process using respirometric monitoring method in hermetic rotary reactor. J. Clean. Prod. 121, 169-175 (2016).

38. Sánchezmonedero, M. A. et al. Greenhouse gas emissions during composting of two-phase olive mill wastes with different agroindustrial by-products. Chemosphere 81(1), 18-25 (2010).

39. Ros, M., Garcia, C. \& Hernandez, T. A full-scale study of treatment of pig slurry by composting: kinetic changes in chemical and microbial properties. Waste Manag. 26(10), 1108-1118 (2006).

40. Wu, C., Li, W., Wan, K. \& Li, Y. Usage of pumice as bulking agent in sewage sludge composting. Bioresour. Technol. 190, 516-521 (2015).

41. Das, M. et al. Co-composting of physic nut (Jatropha curcas) deoiled cake with rice straw and different animal dung. Bioresour. Technol. 102(11), 6541-6546 (2011).

42. Guo, R. et al. Effect of aeration rate, $\mathrm{C} / \mathrm{N}$ ratio and moisture content on the stability and maturity of compost. Bioresour. Technol. 112, 171-178 (2012)

43. Gigliotti, G. et al. Co-composting of olive husks with high moisture contents: Organic matter dynamics and compost quality. Int. Biodeterior. Biodegr. 67, 8-14 (2012). 


\section{Acknowledgements}

This study was supported by the National Natural Science Foundation of China (Nos. 51708187 and 51878216), the Pre-research Project of Heilongjiang Sciences Academy (YY2020SW01) and the Outstanding Youth Science Foundation of Heilongjiang Sciences Academy (CXJQ2018SW01).

\section{Author contributions}

L.M.: conceived and designed the experiments, wrote the paper. W.L.: conceived and designed the experiments. X.Z.: contributed reagents, materials, analysis tools or data. S.Z.: analyzed and interpreted the data. Y.Z., L.C.: performed the experiments.

\section{Competing interests}

The authors declare no competing interests.

\section{Additional information}

Correspondence and requests for materials should be addressed to W.L.

Reprints and permissions information is available at www.nature.com/reprints.

Publisher's note Springer Nature remains neutral with regard to jurisdictional claims in published maps and institutional affiliations.

(c) (i) Open Access This article is licensed under a Creative Commons Attribution 4.0 International License, which permits use, sharing, adaptation, distribution and reproduction in any medium or format, as long as you give appropriate credit to the original author(s) and the source, provide a link to the Creative Commons licence, and indicate if changes were made. The images or other third party material in this article are included in the article's Creative Commons licence, unless indicated otherwise in a credit line to the material. If material is not included in the article's Creative Commons licence and your intended use is not permitted by statutory regulation or exceeds the permitted use, you will need to obtain permission directly from the copyright holder. To view a copy of this licence, visit http://creativecommons.org/licenses/by/4.0/.

(C) The Author(s) 2021 